\title{
HAMILTONIAN AND PANCYCLIC GRAPHS IN THE CLASS OF SELF-CENTERED GRAPHS WITH RADIUS TWO
}

\author{
PAVEL HRNČIAR \\ AND \\ Gabriela Monoszová \\ Department of Mathematics, Faculty of Natural Sciences \\ Matej Bel University, Tajovského 40, 97401 Banská Bystrica, Slovakia \\ e-mail: Pavel.Hrnciar@umb.sk \\ Gabriela.Monoszova@umb.sk
}

\begin{abstract}
The paper deals with Hamiltonian and pancyclic graphs in the class of all self-centered graphs of radius 2. For both of the two considered classes of graphs we have done the following. For a given number $n$ of vertices, we have found an upper bound of the minimum size of such graphs. For $n \leq 12$ we have found the exact values of the minimum size. On the other hand, the exact value of the maximum size has been found for every $n$. Moreover, we have shown that such a graph (of order $n$ and) of size $m$ exists for every $m$ between the minimum and the maximum size. For $n \leq 10$ we have found all nonisomorphic graphs of the minimum size, and for $n=11$ only for Hamiltonian graphs.
\end{abstract}

Keywords: self-centered graph with radius 2, Hamiltonian graph, pancyclic graph, size of graph.

2010 Mathematics Subject Classification: 05C12, 05C35, $05 \mathrm{C} 45$.

\section{REFERENCES}

[1] J. Akiyama, K. Ando and D. Avis, Miscellaneous properties of equi-eccentric graphs, in: Convexity and Graph Theory, Proceedings of the Conference on Convexity and Graph Theory (Jerusalem, 1981), M. Rosenfeld and J. Zaks (Ed(s)), (North-Holland Math. Stud. 87, North-Holland, Amsterdam, 1984) 13-23.

doi:10.1016/S0304-0208(08)72802-0

[2] F. Buckley, Self-centered graphs with a given radius, Congr. Numer. 23 (1979) $211-215$. 
[3] F. Buckley and F. Harary, Distance in Graphs (Addison-Wesley Publishing Company, Redwood City, CA, 1990).

[4] J.L. Gross, J. Yellen and P. Zhang, Handbook of Graph Theory (CRC Press, 2014).

[5] A. Haviar, P. Hrnčiar and G. Monoszová, Eccentric sequences and cycles in graphs, Acta Univ. M. Belii Ser. Math. 11 (2004) 7-25.

[6] P. Hrnčiar, On cycles in graphs with specified radius and diameter, Acta Univ. M. Belii Ser. Math. 20 (2012) 7-10. 
[7] P. Hrnčiar and G. Monoszová, Minimal two-valued eccentric sequences, Int. J. Pure Appl. Math. 84 (2013) 139-152.

[8] D. Palumbíny, Sul numero minimo degli spigoli di un singramma di raggio e diametro eguali a due, Ist. Lombardo Accad. Sci. Lett. Rend. A 106 (1972) 704-712, in Italian.

Received 17 May 2016

Revised 24 November 2016

Accepted 25 January 2017 